\title{
The Relationship between Cyberbullying Victimization and Depression: The Moderating Effects of Gender and Age
}

\author{
Jamal Almenayes \\ Department of Mass Communication, Kuwait University, Kuwait, Kuwait \\ Email:jamal@almenayes.com
}

How to cite this paper: Almenayes, J. (2017) The Relationship between Cyberbullying Victimization and Depression: The Moderating Effects of Gender and Age. Social Networking, 6, 215-223.

https://doi.org/10.4236/sn.2017.63014

Received: March 30, 2017

Accepted: June 5, 2017

Published: June 8, 2017

Copyright $\odot 2017$ by author and ScientificResearch Publishing Inc.

This work is licensed under the

CreativeCommons Attribution

International

License (CC BY 4.0).

http://creativecommons.org/licenses/by/4.0/

\begin{abstract}
Using cross-sectional, self-report data this study investigates the effect of cyberbullying victimization on depression with gender and age as moderating factors. The sample $(n=1400)$ consisted of students in a large public university in Kuwait. First, the results show that gender was a significant predictor of depression with females being higher than males on this measure. Second, age was a significant negative predictor with older subjects less likely than younger ones to experience depression. Finally, the study examined the interaction effect of gender and age with cyber-victimization. Results indicate that there is no significant interaction effect between gender and cyber-victimization. However, a significant interaction effect exists between age and cyber-victimization. Older subjects are likely to suffer more depression when exposed to cyber-victimization than younger ones.
\end{abstract}

\section{Keywords}

Cyberbullying, Cyber-Victimization, Depression, Social Media, Victimization, Kuwait

\section{Introduction}

Cyberbullying or electronic aggression or online harassment has become a major public health issue with numerous negative consequences over the past few years, especially among youth. There is no standard definition of the phenomenon as of yet. However, some commonly used definitions include "willful and repeated harm inflicted through the use of computers, cell phones, and other electronic devices" [1]. Another definition of cyberbullying is "an aggressive, intentional act carried out by a group or individual, using electronic forms of contact, repeatedly and over time against a victim who cannot easily defend him or 
herself" [2]. Most previous research on cyberbullying has concentrated on middle and high school students mainly because these have always been the traditional contexts in which bullying occurs. The incidence rate is reported to be from $20 \%$ to $40 \%$ [3].

Young victims of cyberbullying report higher levels of depression and suicidal thoughts. They also experience increased emotional distress, externalized hostility, and delinquency in comparison to non-victims [4]. Furthermore, the severity of depression in victims is associated with the degree and severity of cyberbullying [5]. These negative consequences are also found in traditional bullying. However, unlike traditional bullying, there is evidence that perpetrators of cyberbullying also experience symptoms of depression and suicidal thoughts [6], [7].

Most previous research on cyberbullying has focused largely on younger adolescents. However, more recent work on the subject has begun to study this phenomenon in college students. This new shift in focus is logical given that the vast majority of heavy users of cyber technology are emerging adults [2]. Incidence rates of cyberbullying among emerging adults and college students are estimated to be around $10 \%-15 \%$ [8], [9]. Some studies have suggested that cyberbullying among college students may reflect a continuation of bullying behavior from high school but in a different context, one which is digital in nature [10]. For example, a study of college students found that motivations for cyberbullying in emerging adults are similar to those in young adolescents [11]. Another study conducted in Britain found that college students found cyberbullying is more acceptable than physical bullying but less acceptable than verbal bullying [12].

Research on the consequences of cyberbullying in college students is sparse but rising. One study found that cyberbullying is associated with depression, anxiety, and suicidal thoughts in victims [9]. In another study of college students in Greece has found that cyberbullying perpetrators have callous-unemotional traits, and depression was found in both bullies and victims [13]. In all these studies there was little or no accounting for sex differences or age in the subject pool.

Research on the effect of age on cyberbullying produced mixed results. The majority of cyberbullying studies were done on school children and young adolescents, a group that is believed to be vulnerable [14]. A large number of studies found no correlation between age and cyberbullying victimization [1], [5], [15]. For example, a study done in the United Kingdom among school students aged between 11 and 16 years old found no effect of age on cyberbullies or cyber victims [2]. However, the study found a significant interaction between age and gender in the context of e-mail bullying and the use of instant messaging. The younger students felt the effect of e-mail bullying to be worse than girls of the same age; however, this difference disappears in older age group. Also, older boys were more likely to be e-mail bullies than younger boys.

The purpose of this study is to examine the relationship between cyberbully- 
ing victimization and depression in both males and females. Females are more likely than males to be victims of cyberbullying and are more susceptible to depression [16]. Moreover, the study seeks to find out if age plays a role in the relationship between cyberbullying victimization among college students. Based on a review of previous research, it was hypothesized that those who experience cyberbullying would have higher rates of depression than others with this being truer in females. Also, older subjects are less likely to be victimized than younger ones. With that in mind, the current study seeks to answer three research questions.

\section{Research Questions}

RQ1: What is the relationship between cyber-victimization and depression?

RQ2: Are there any gender differences in the relationship between cyber-victimization and depression?

RQ3: Is there any age difference in the relationship between cyber-victimization and depression?

\section{Method}

\subsection{Sample and Procedures}

The study is based on cross-sectional survey data where respondents filled out a paper questionnaire. The data were collected from a sample of purposively selected college students reflecting the fact that youth constitute the majority of social media users. College students enrolled in mass communication courses at a large state university in Kuwait were asked to participate in this study. The questionnaires were distributed over a span of three months beginning in March 2016. The final sample size was 1400 . The language used in the questionnaire was Arabic.

The responses were both anonymous and confidential, and students were free not to take part in the survey if they wish. The participants' age ranged from 17 to 49 with $91 \%$ falling in the 18 to 26 years range. The mean age is 21.87 years. The sample consisted of 487 (34.8\%) males and 913 (65.2\%) females. The gender sample distribution is reflective of the enrollment profile of the university students which is approximately $70 \%$ female. The forms were distributed during regular class sessions. The instrument included Likert scale questions, used to quantify the individual's perceptions, attitudes, and behaviors, as well as demographics and questions about media use behavior.

\subsection{Measurement}

\subsubsection{Cyber-Victimization}

A five-item Likert scale was used to quantify social the cyber-victimization variable. The measurement was based on the E-Victimization Scale developed and validated by Lam and $\mathrm{Li}$ [17]. The response set range was from "strongly disagree" (1) to "strongly agree" (5). Table 1 shows the English version of the items that were originally in Arabic along with descriptive statistics. 
Table 1. Descriptive statistics of the cyber-victimization scale.

\begin{tabular}{|c|c|c|c|}
\hline How many times during the past 30 days? & M & $\mathrm{SD}$ & Skewness \\
\hline 1. You received a text message that made fun of you or made you angry. & 1.80 & 0.94 & 1.03 \\
\hline $\begin{array}{l}\text { 2. Someone posted a comment on your social } \\
\text { media account that upset you. }\end{array}$ & 1.64 & 0.93 & 1.29 \\
\hline 3. You felt afraid to enter social media. & 1.42 & 0.81 & 2.20 \\
\hline 4. Someone posted content about you that you don't want others to see. & 1.35 & 0.73 & 2.18 \\
\hline 5. Someone impersonated you on social media to make fun of you. & 1.24 & 0.66 & 3.02 \\
\hline
\end{tabular}

\subsubsection{Depression}

Depression was measured using a six-item Likert scale based on the Patient health questionnaire (PHQ) [18]. The original questionnaire consisted of 3-page self-report which is not practical for the purpose of this study. That is why only six of the most relevant symptoms were selected to be included in the survey. The response set range was from "strongly disagree" (1) to "strongly agree" (5). Table 2 shows the English version of the items that were originally in Arabic along with descriptive statistics.

\subsubsection{Age and Gender}

Age was a continuous variable measured in years, and gender was a dichotomous variable with males receiving a value of 1 and females receiving a value of 2 .

\section{Results}

\subsection{Cyber-Victimization}

For the purpose of dimension-reduction, the five-item cyber-victimization scale was subjected to factor analysis (Table 3 ). The results yielded a single factor solution with factor loadings ranging from 0.60 to 0.79 and explaining $51 \%$ of the variance and an Eigenvalue of 2.56. Cronbach's alpha was 0.75 indicating the scale has good reliability and is suitable for further analysis.

\subsection{Depression}

The six item depression scale was subjected to factor analysis to determine its dimensionality (Table 4). The results indicate a single factor solution indicating its unidimensionality. Factor loadings ranged between 0.63 and 0.76 explaining $48 \%$ of the variance and an Eigenvalue of 2.89. Cronbach's alpha was 0.78 indicating the scale was reliable for further analysis. Depression is the dependent variable constituting the focus of this study.

\subsection{Cyber-Victimization and Depression}

The first research question asked if there is a relationship between cyber-victimization and depression. To answer this question the study employed hierarchical linear regression analysis where cyber-victimization was entered as the independent variable and depression as the dependent variable. As Table 5 shows results of this analysis indicate that cyber-victimization is a significant 
Table 2. Descriptive statistics of the depression scale.

\begin{tabular}{lccc}
\hline \multicolumn{1}{c}{ How many times during the past two weeks? } & $\mathrm{M}$ & SD & Skewness \\
\hline 1. You felt apathetic and not enjoying the things you normally enjoy. & 2.39 & 1.05 & 0.80 \\
2. You felt sad, depressed and hopeless. & 2.22 & 1.09 & 0.81 \\
3. Found it difficult to fall asleep or sleep a lot. & 2.86 & 1.26 & 0.27 \\
4. Felt tired and lacking in energy. & 2.81 & 1.15 & 0.41 \\
5. Lost your appetite or overeating. & 2.53 & 1.28 & 0.45 \\
6. Found difficulty concentrating when doing something like reading. & 2.41 & 1.21 & 0.55 \\
\hline
\end{tabular}

Table 3. Factor analysis and reliability of the cyber-victimization scale.

\begin{tabular}{|c|c|}
\hline Item & Factor loading \\
\hline 1. You received a text message that made fun of you or made you angry. & 0.60 \\
\hline 2. Someone posted a comment on your social media account that upset you. & 0.74 \\
\hline 3. You felt afraid to enter social media. & 0.70 \\
\hline 4. Someone posted content about you that you don't want others to see. & 0.79 \\
\hline 5. Someone impersonated you on social media to make fun of you. & 0.72 \\
\hline Eigenvalue & 2.56 \\
\hline$\%$ of variance explained & 51 \\
\hline Cronbach's alpha & 0.75 \\
\hline
\end{tabular}

Table 4. Factor analysis and reliability of the depression scale.

\begin{tabular}{lc}
\hline \multicolumn{1}{c}{ Item } & Factor loading \\
\hline 1. You felt apathetic and not enjoying the things you normally enjoy. & 0.63 \\
2. You felt sad, depressed and hopeless. & 0.67 \\
3. Found it difficult to fall asleep or sleep a lot. & 0.72 \\
4. Felt tired and lacking in energy. & 0.76 \\
5. Lost your appetite or overeating. & 0.68 \\
6. Found difficulty concentrating when doing something like reading & 0.67 \\
E of variance explained & 2.89 \\
Cronbach's alpha & 48 \\
\hline
\end{tabular}

Table 5. Regressing depression on cyber-victimization with gender and age as controls and interaction effects.

\begin{tabular}{ccccc}
\hline Variable & $B$ & $S E B$ & $\beta$ & $T$ \\
\hline Block 1 & & & & \\
Gender & 0.30 & 0.057 & $0.14^{* *}$ & 5.30 \\
Age & -0.02 & 0.007 & $-0.08^{* *}$ & -3.22 \\
Block 2 & & & & \\
Cyber-victimization & 0.24 & 0.026 & $0.23^{* *}$ & 9.09 \\
Block 3 (Interactions) & & & & \\
Gender*Victimization & 0.08 & 0.04 & 0.06 & 1.81 \\
Age*Victimization & 0.009 & 0.002 & $0.19^{* *}$ & 5.54 \\
\hline
\end{tabular}

Note. Block 1, $\mathrm{R}=0.186, \mathrm{R} 2=0.035, \mathrm{~F}=25, \mathrm{df}=2$. Block $2, \mathrm{R}=0.298, \mathrm{R} 2=0.089, \mathrm{~F}=45, \mathrm{df}=3, \mathrm{Block} 3, \mathrm{R}$ $=0.214, \mathrm{R} 2=0.046, \mathrm{df}=4,{ }^{* *} p \leq 0.001, \mathrm{n}=1400$. 
positive predictor of depression $(\beta=0.23, T=9.09, p \leq 0.001)$. This indicates that those who are cyber-bullied are likely to become depressed.

\subsection{The Main Effects of Gender and Age}

Using the same regression analysis gender and age were entered as a single block to examine their main effects. As we can see from Table 5 gender is a strong positive predictor of depression ( $\beta=0.14, T=5.30, p \leq 0.001)$. Given the way, gender was coded this means that females are more prone to depression than males. Age was a strong negative predictor of depression $(\beta=-0.08, T=-3.22, p$ $\leq 0.001)$. This means the older a person is, the less he or she is susceptible to depression.

\subsection{The Interaction Effects of Gender and Age with Cyber-Victimization}

To examine possible interaction effects of gender and age with cyber-victimization two new variables were created. They are a product of the multiplying each of the two variables with cyber-victimization. These variables were then regressed on depression to assess the interaction effect. These variables were entered into the regression model after controlling for the main effect of gender and age. As we can see in Table 5, there is no significant interaction effect between gender and cyber-victimization meaning the relationship between gender and depression is linear regardless of cyber-victimization. In other words, there is no evidence that cyber-victimization differentiate between males and females.

A more interesting finding is seen in the interaction between cyber-victimization and age. The interaction between age and cyber-victimization is positive and quite significant $(\beta=0.19, T=5.54, p \leq 0.001)$. This is a reversal of the main effect of age and depression which was negative. What this result indicates is the effect of cyber-victimization on depression when it exists is amplified by age. In other words, age alone has a negative relationship with depression. However, when cyber-victimization does happen, its effect on depression is elevated by age.

\section{Discussion}

This study investigated the effect of cyberbullying victimization on feelings of depression among college students. The moderating effects of gender and age were also examined. The results indicate that cyber-victimization is a significant positive predictor of feelings of depression. This is consistent with findings in previous studies on this subject [4] [5] [6] [14]. The effects of gender and age were examined independently. Results show that females are more prone to depression than males regardless of cyberbullying victimization. Similar results were found in numerous studies using various methods, [19], [20], [21]. This can be related to life cycle events that affect girls more than boys. One such event is weight gain associated with puberty and body dissatisfaction with girls [22], [23], [24]. Rosenblum and Lewis [25] found that gender differences in body dissatisfaction appeared by 13 , became reliable by age 15 , and continued at 18 , with 
girls increasing and boys decreasing in dissatisfaction. Other studies have found that body dissatisfaction and low self-esteem (both more prevalent in girls) were the most important risk factors for depression [26] [27]. The current study confirms these finding with data showing females more prone to depression than males.

Age was a significant negative predictor of depression, meaning older individuals in the sample age group (18 - 26) are less likely than younger ones to experience feelings of depression. This could be the result of stress in a university setting with younger students adjusting to a new environment and facing pressure from academic obligations and uncertainty about their prospects. In contrast older students, who are about to graduate, experience less of these pressures leading to less anxiety and depression. The main effect of age on depression was reversed when cyberbullying was entered as a moderating variable. This means that while older students tend to experience less depression, in general, they experience more depression when subjected to cyberbullying. A possible explanation for this is older students have more to lose when they fall victim to behaviors such as defamation, denigration and harmful lies since it might harm their career prospects that are fast approaching. In contrast, younger students have less immediacy when it comes to the effect of cyber-victimization on their career prospects resulting in lower levels of depression.

\section{Conclusion}

Cyberbullying constitutes a serious problem in today's networked society. Communication technology is progressing at a rapid rate with social and psychological consequences we are just beginning to understand. Depression among adolescents and emerging adults as a result of cyberbullying is well documented. However, given the dearth of research into the mediating factors influencing the relationship between cyberbullying and depression, the researcher offers the present study as one step towards a better understanding of the conditional effects moderating the relationship between cyberbullying and depression. Future research should examine possible consequences of the modality of cyberbullying. For example, is there any difference between private and public cyberbullying? We might find a difference, for example, between bullying through direct messages which only the victim can see and public posts that are available to the general public. Similarly, does the presence of visual elements make a difference on the effect of cyberbullying? What about the app used? In the current research, all apps were treated similarly and lumped under the generic label "social media." Future research might want to classify cyberbullying based on the characteristics of the app through which it occurred. Finally, future research could benefit greatly from employing various research methods. Most studies on cyberbullying, including this one, have relied on cross-sectional self-reports through sample surveys. Our understanding of this phenomenon might be enhanced by using experiments in which various intervening variables are manipulated to measure their possible moderating effects. 


\section{Acknowledgements}

This research was supported by Kuwait University Research Sector grant no. AM07/15.

\section{References}

[1] Patchin, J.W. and Hinduja, S. (2016) Bullying Today: Bullet Points and Best Practices. Sage Publications (Corwin Press), Thousand Oaks.

[2] Smith, P.K., Mahdavi, J., Carvalho, M., Fisher, S., Russell, S. and Tippett, N. (2008) Cyberbullying: Its Nature and Impact in Secondary School Pupils. Journal of Child Psychology and Psychiatry, 49, 376-385. https://doi.org/10.1111/j.1469-7610.2007.01846.x

[3] Tokunaga, R.S. (2010) Following You Home from School: A Critical Review and Synthesis of Research on Cyberbullying Victimization. Computers in Human Behavior, 26, 277-287.

[4] Ybarra, M.L., Mitchell, K.J., Wolak, J. and Finkelhor, D. (2006) Examining Characteristics and Associated Distress Related to Internet Harassment: Findings from the Second Youth Internet Safety Survey. Pediatrics, 118, 1169-1177. https://doi.org/10.1542/peds.2006-0815

[5] Didden, R., Scholte, R.H.J., Korzilius, H., de Moor, J.M.H., Vermeulen, A., O’Reilly, M., Lang, R. and Lancioni, G.E. (2009) Cyberbullying among Students with Intellectual and Developmental Disability in Special Education Settings. Developmental Neurorehabilitation, 12, 146-151. https://doi.org/10.1080/17518420902971356

[6] Bonanno, R.A. and Hymel, S. (2013) Cyber Bullying and Internalizing Difficulties: Above and beyond the Impact of Traditional Forms of Bullying. Journal of Youth and Adolescence, 42, 685-697. https://doi.org/10.1007/s10964-013-9937-1

[7] Van Geel, M., Vedder, P. and Tanilon, J. (2014) Relationship between Peer Victimization, Cyberbullying, and Suicide in Children and Adolescents: A Meta-Analysis. JAMA Pediatrics, 168, 435-442. https://doi.org/10.1001/jamapediatrics.2013.4143

[8] Kraft, E. and Wang, J. (2010) An Exploratory Study of the Cyberbullying and Cyberstalking Experiences and Factors Related to Victimization of Students at a Public Liberal Arts College. International Journal of Technoethics, 1, 74-91. https://doi.org/10.4018/jte.2010100106

[9] Schenk, A. and Fremouw, W. (2012) Prevalence, Psychological Impact, and Coping of Cyberbully Victims among College Students. Journal of School Violence, 11, 21 37. https://doi.org/10.1080/15388220.2011.630310

[10] Cowie, H.A. (2013) Cyberbullying and Its Impact on Young People's Emotional Health and Well-Being. The Psychiatrist, 37, 167-170.

https://doi.org/10.1192/pb.bp.112.040840

[11] Rafferty, R. and Vander Ven, T. (2014) "I Hate Everything about You": A Qualitative Examination of Cyberbullying and On-Line Aggression in a College Sample. Deviant Behavior, 35, 364-377. https://doi.org/10.1080/01639625.2013.849171

[12] Boulton, M., Lloyd, J., Down, J. and Marx, H. (2012) Predicting Undergraduates' Self-Reported Engagement in Traditional and Cyberbullying from Attitudes. $\mathrm{Cy}^{-}$ berpsychology, Behavior and Social Networking, 15, 141-147. https://doi.org/10.1089/cyber.2011.0369

[13] Kokkinos, C.M.N. and Antoniadou, A.M. (2014) Cyber-Bullying: An Investigation of the Psychological Profile of University Student Participants. Journal of Applied 
Developmental Psychology, 35, 204-214.

[14] Li, Q. (2007) New Bottle But Old Wine: A Research of Cyber-Bullying in Schools. Computers in Human Behavior, 23, 1777-1791.

[15] Varjas, K., Talley, J., Meyers, J., Parris, L. and Cutts, H. (2010) High School Students' Perceptions of Motivations for Cyberbullying: An Exploratory Study. Western Journal of Emergency Medicine, 3, 269-273.

[16] American College Health Association (2009) National College Health Assessment Spring 2008 Reference Group Data Report (Abridged): The American College Health Association. Journal of American College Health, 57, 477-488. https://doi.org/10.3200/JACH.57.5.477-488

[17] Lam, L.T. and Li, Y. (2013) The Validation of the E-Victimisation Scale (E-VS) and the E-Bullying Scale (E-BS) for Adolescents. Computers in Human Behavior, 29, 3 7.

[18] Spitzer, R.L., Kroenke, K. and Williams, J.B.W. (1999) Validation and Utility of a Self-Report Version of PRIME-MD: The PHQ Primary Care Study. JAMA, 282, 1737-1744. https://doi.org/10.1001/jama.282.18.1737

[19] Galambos, N.L. (2004) Gender and Gender Role Development in Adolescence. In: Lerner, R.M. and Steinberg, L., Eds., Handbook of Adolescent Psychology, 2nd Edition, John Wiley and Sons, Hoboken, 233-261. https://doi.org/10.1002/9780471726746.ch8

[20] Bennett, D.S., Ambrosini, P.J., Kudes, D., Metz, C. and Rabinovich, H. (2005) Gender Differences in Adolescent Depression: Do Symptoms Differ for Boys and Girls? Journal of Affect Disorders, 89, 35-44.

[21] Bearman, S.K. and Stice, E. (2008) Testing a Gender Additive Model: The Role of Body Image in Adolescent Depression. Journal of Abnormal Child Psychology, 36, 1251-1263. https://doi.org/10.1007/s10802-008-9248-2

[22] Lai, C. (2011) Major Depressive Disorder: Gender Differences in Symptoms, Life Quality, and Sexual Function. Journal of Clinical Psychopharmacology, 31, 39-44. https://doi.org/10.1097/JCP.0b013e318205a670

[23] Ge, X., Conger, R.D. and Elder, G.H. (1996) Coming of Age Too Early: Pubertal Influences on Girls' Vulnerability to Psychological Distress. Child Development, 67, 3386-3400. https://doi.org/10.2307/1131784

[24] Graber, J.A., Brooks-Gunn, J., Paikoff, R.L. and Warren, M.P. (1994) Prediction of Eating Problems: An 8-Year Study of Adolescent Girls. Developmental Psychology, 30, 823-834. https://doi.org/10.1037/0012-1649.30.6.823

[25] Rosenblum, G.D. and Lewis, M. (1999) The Relations among Body Image, Physical Attractiveness and Body Mass in Adolescence. Child Development, 70, 50-64. https://doi.org/10.1111/1467-8624.00005

[26] Allgood-Merten, B., Lewinsohn, P.M. and Hops, H. (1990) Sex Differences and Adolescent Depression. Journal of Abnormal Psychology, 99, 55-63. https://doi.org/10.1037/0021-843X.99.1.55

[27] Wichstrøm, L. (1999) The Emergence of Gender Difference in Depressed Mood during Adolescence: The Role of Intensified Gender Socialization. Developmental Psychology, 35, 232-245. https://doi.org/10.1037/0012-1649.35.1.232 
Submit or recommend next manuscript to SCIRP and we will provide best service for you:

Accepting pre-submission inquiries through Email, Facebook, LinkedIn, Twitter, etc. A wide selection of journals (inclusive of 9 subjects, more than 200 journals)

Providing 24-hour high-quality service

User-friendly online submission system

Fair and swift peer-review system

Efficient typesetting and proofreading procedure

Display of the result of downloads and visits, as well as the number of cited articles Maximum dissemination of your research work

Submit your manuscript at: http://papersubmission.scirp.org/

Or contact sn@scirp.org 